\title{
Motor nerve conduction velocities in Leigh's encephalomyelopathy
}

\author{
A. MOOSA
}

From the Department of Paediatrics and Neonatal Medicine, Institute of Child Health, Hammersmith Hospital, London

SUMMARY Slowed motor nerve conduction velocities were found in 3 of 4 cases of Leigh's subacute necrotising encephalopathy. 2 of the patients are sibs, one of whom is clinically normal apart from lactic acidosis and slowed motor nerve conduction velocities.

Measurement of conduction velocity of peripheral nerves has greatly facilitated the diagnosis of peripheral neuropathy in infancy and childhood and has led to the recognition of peripheral nerve involvement in an increasing number of childhood disorders (Gamstorp, 1968). These include disorders where the pathology is mainly confined to the peripheral nervous system such as Guillain-Barré syndrome, peroneal muscular atrophy, and Dejerine-Sottas neuropathy, and those where both central and peripheral nervous systems are affected. Examples of the latter include metachromatic leucodystrophy (Fullerton, 1964), globoid cell leucodystrophy (Dunn et al., 1969), Cockayne's syndrome (Moosa and Dubowitz, 1970), and Fabry's disease (Kocen and Thomas, 1970). 4 patients with Leigh's necrotising encephalomyelopathy are reported, 3 of whom had slowed motor nerve conduction velocities.

\section{Case reports (Tables 1, 2)}

Case 1. A 14-month-old boy presented with a history of episodic vomiting and failure to thrive from age 6 months. Though development had been normal until then, he had made no further motor progress. Height and weight were below the 3rd centile. He was conscious but irritable, and lay with his thighs abducted at the hips and legs flexed at knees, but with upper arms abducted and internally rotated at the shoulders, forearms extended at the elbcws, and fists clenched. He was generally hypotonic but not overtly weak. Reflexes were present but sluggish. Sensation was intact. No abnormal eye movements or respirations were observed.

Investigation showed a persistent ketoacidosis and raised blood lactate and pyruvate (see Table 2).

Received 10 May 1977.
Table 1 Clinical findings in Leigh's syndrome

\begin{tabular}{|c|c|c|c|c|}
\hline & \multicolumn{4}{|c|}{ Case no. } \\
\hline & 1 & 2 & 3 & 4 \\
\hline Age at presentation (months) & 14 & 30 & Birth & 4 \\
\hline Normal early milestones & + & + & + & - \\
\hline Vomiting & + & + & - & + \\
\hline Failure to thrive & + & + & - & + \\
\hline Intellectual and motor & & & & \\
\hline regression & + & + & - & - \\
\hline Hypotonia & + & + & - & - \\
\hline Abnormal eye movements & - & + & - & + \\
\hline Abnormal respirations & - & + & - & + \\
\hline Extensor spasms & + & + & - & - \\
\hline Spastic diplegia & - & - & - & + \\
\hline
\end{tabular}

Motor nerve conduction velocities were slow (Table 3). Sural nerve biopsy showed evidence of myelin breakdown on electron microscopy. A clinical diagnosis of Leigh's syndrome was made and he was treated with thiamine hydrochloride and glutamine without effect. He died 6 weeks later from a fulminating chest infection and necropsy confirmed the diagnosis of Leigh's syndrome (case fully reported elsewhere (Moosa, 1975)).

Case 2. A 3 $\frac{1}{2}$-year-old boy presented with a history of episodic vomiting and failure to thrive from age 10 months. Development had been normal until 10 months, and he was able to walk with assistance, but by 20 months he had acquired no new skills. By 30 months he had regressed and was unable to walk. Height and weight were below the 3rd centile. He was irritable and intermittently showed rotary eye movements on looking upwards, which was often associated with irregular respirations. His fundi showed macular pigmentation. He was hypotonic but not weak and had brisk reflexes. A kyphoscoliosis was present. 
Table 2 Biochemical findings in Leigh's syndrome

\begin{tabular}{|c|c|c|c|c|c|}
\hline & Normal & Case 1 & Case 2 & Case 3 & Case 4 \\
\hline $\begin{array}{l}\text { Blood pH } \\
\text { PCO }_{2}(\mathrm{mmHg}) \\
\text { Base excess }(\mathrm{mmol} / 1)\end{array}$ & & $\begin{array}{l}7 \cdot 35-7 \cdot 47 \\
25-33 \\
-4 \text { to }-6\end{array}$ & $\begin{array}{l}7 \cdot 28-7 \cdot 42 \\
21-29 \\
-6 \text { to }-13\end{array}$ & $\begin{array}{l}7 \cdot 23-7 \cdot 41 \\
15-21 \\
-8 \text { to }-12\end{array}$ & $\begin{array}{l}7 \cdot 26-7 \cdot 46 \\
21-36 \\
-6 \text { to }-11\end{array}$ \\
\hline $\begin{array}{l}\text { Blood lactate }(\mathrm{mg} / 100 \mathrm{ml}) \\
\text { Blood pyruvate }(\mathrm{mg} / 100 \mathrm{ml}) \\
\text { Betahydroxy butyrate }(\mathrm{mg} / 100 \mathrm{ml})\end{array}$ & $\begin{array}{l}9-16 \\
1 \cdot 7 \\
0 \cdot 1-0 \cdot 6\end{array}$ & $\begin{array}{l}19-29 \\
0 \cdot 2-1 \cdot 2 \\
8-25\end{array}$ & $\begin{array}{l}21-61 \\
0 \cdot 4-2 \cdot 2 \\
-\end{array}$ & $\begin{array}{l}56-67 \\
1 \cdot 4-2 \cdot 4 \\
-\end{array}$ & $\begin{array}{l}20-45 \\
1 \cdot 2-3 \cdot 3 \\
2 \cdot 4\end{array}$ \\
\hline $\begin{array}{l}\text { Plasma alanine } \\
\text { Urine alanine } \\
\text { CSF protein }(g / l)\end{array}$ & & $\uparrow_{0 \cdot 38}^{\uparrow}$ & $\uparrow$ & $\begin{array}{l}\mathbf{N} \\
\mathbf{N}\end{array}$ & $\uparrow_{0.62}$ \\
\hline $\begin{array}{l}\text { Urinary inhibitor } \\
\text { RBC transketolase (units)* } \\
\text { + thyamine pyrophosphate } \\
\text { effect of thyamine } \\
\text { pyrophosphate }(\%)\end{array}$ & $\begin{array}{r}55 \\
58 \\
6\end{array}$ & & $\begin{array}{l}- \\
58 \\
84 \\
37\end{array}$ & $\begin{array}{l}+ \\
62 \\
80 \\
37\end{array}$ & - \\
\hline
\end{tabular}

*1 unit = 1 nmol NADH formed $/$ min per ml packed $\mathbf{R B C}$.

Conversion: Traditional units to $S I$-Lactate: $1 \mathrm{mg} / 100 \mathrm{ml} \approx 0.111 \mathrm{mmol} / 1$. Pyruvate: $1 \mathrm{mg} / 100 \mathrm{ml} \approx 113.5 \mu \mathrm{mol} / 1$. PCO $: 1 \mathrm{mmHg} \approx$ $0 \cdot 133 \mathrm{kPa}$.

Table 3 Motor-nerve conduction velocities in Leigh's syndrome

\begin{tabular}{|c|c|c|c|}
\hline & \multirow[b]{2}{*}{ Age (m) } & \multicolumn{2}{|c|}{ Velocity $(\mathrm{m} / \mathrm{s})$} \\
\hline & & Ulnar & Posterior tibial \\
\hline Case 1 & $\begin{array}{l}14 \\
17 \\
19\end{array}$ & $\begin{array}{l}25 \cdot 0 \\
25 \cdot 8 \\
26 \cdot 4 \\
23 \cdot 4^{*}\end{array}$ & $\begin{array}{l}18 \cdot 5 \\
\frac{1}{18} \cdot 4 \\
17 \cdot 5^{*}\end{array}$ \\
\hline Case 2 & $\begin{array}{l}29 \\
35 \\
42\end{array}$ & $\begin{array}{l}31 \cdot 0 \\
39 \cdot 0 t \\
34 \cdot 5\end{array}$ & $\begin{array}{l}24 \cdot 0 \\
33 \cdot 0+ \\
26 \cdot 0\end{array}$ \\
\hline Case 3 & $\begin{array}{l}1 \\
5 \\
9\end{array}$ & $\begin{array}{l}23 \cdot 4 \\
30 \cdot 0 \\
34 \cdot 0\end{array}$ & $\begin{array}{l}-\overline{20} \cdot 4 \\
27 \cdot 5\end{array}$ \\
\hline Case 4 & 4 & $42 \cdot 0$ & $31 \cdot 0$ \\
\hline Normal (mean \pm 1 SD) & $\begin{array}{l}\text { Birth } \\
6 \\
12 \\
36\end{array}$ & $\begin{array}{l}27 \cdot 7 \pm 2 \cdot 4 \\
41 \cdot 7 \pm 3 \cdot 0 \\
46 \cdot 1 \pm 3 \cdot 0 \\
52 \cdot 5 \pm 3 \cdot 5\end{array}$ & $\begin{array}{l}22 \cdot 2 \pm 2 \cdot 4 \\
32 \cdot 0 \pm 2 \cdot 5 \\
38 \cdot 2 \pm 3 \cdot 3 \\
44 \cdot 2 \pm 1 \cdot 9\end{array}$ \\
\hline
\end{tabular}

*6 weeks after therapy with thiamine.

$\dagger 1$ week after therapy with thiamine tetrafophoral disulphide.

Investigation showed a persistent metabolic acidosis and raised pyruvate and lactate. CSF protein was $0.64 \mathrm{~g} / \mathrm{l}$. Motor conduction velocities were slow. A clinical diagnosis of Leigh's syndrome was made, but the urine contained no inhibitor substance. His RBC transketolase activity was enhanced $35 \%$ in vitro by the addition of thiamine pyrophosphate. For the past year he has received treatment at various times with thiamine derivatives, glutamine, and L-aspartate, without effect. His condition has continued to deteriorate. He now has frequent extensor spasms, has no speech, and the limbs are hypertonic. Both parents are well. The father, but not the mother, has inhibitor substance in his urine. They have one normal and one other affected child (see below).

Case 3. A 9-month-old boy a sib of Case 2. He has been seen since birth and has shown no abnormal signs on examination and is developmentally normal for his age. He has, however, a persistent metabolic acidosis with raised blood lactate and pyruvate. His motor nerve conduction velocities are slow. Urine contains the inhibitor substance of Cooper (Pincus et al., 1969), and RBC transketolase activity was increased by $35 \%$ with the addition of thiamine pyrophosphate.

Case 4. A 4-month-old boy was born small-for-dates (birthweight $2200 \mathrm{~g}$ at term). Mother had oligohydramnios. He had a metabolic acidosis and transient uraemia in the first week of life. At 6 weeks he was noted to have spastic diplegia. He also failed to thrive. By 4 months he was developmentally retarded with height and weight below the 3rd centile. Abnormal rotary eye movements were observed intermittently, often associated with abnormal respirations. He had a persistent metabolic acidosis and raised blood pyruvate and lactate, but Cooper's inhibitor substance was absent. Motor nerve conduction velocities were normal. He died, after smallpox vaccination, from a fulminating chest infection at 7 months of age.

At necropsy (Dr: P. D. Lewis) the tectum of midbrain appeared grey-brown, soft, and necrotic. The necrosis extended caudally into the upper $5 \mathrm{~mm}$ of periaqueductal pons and appeared to extend as a band $1 \mathrm{~mm}$ broad into the floor of the 4th ventricle. The mammillary bodies appeared normal. Histologically there were areas of spongy rarefaction and necrosis (with some preservation of neuronal 
elements) in the centrum medianum of the thalamus, inferior corpora quadrigemina, substantia nigra, cerebral peduncles, periaqueductal grey matter, tegmentum of pons, floor of the 4th ventricle, and dorsal accessory olivary nuclei. The spinal cord and peripheral nerves were normal. These changes and their distribution are characteristic of Leigh's encephalomyelopathy.

Motor nerve conduction velocities. The ulnar and posterior tibial conduction velocities are given in Table 3 and plotted in Figs. 1 and 2. All patients

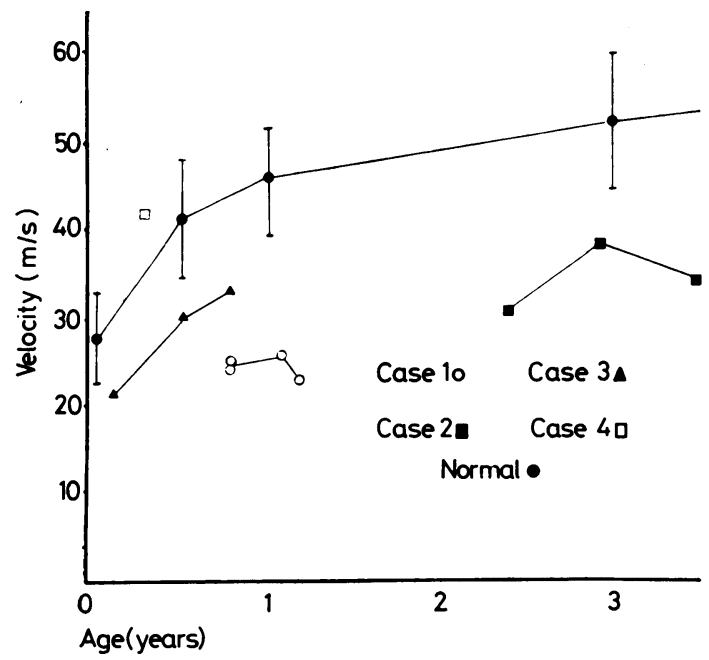

Fig. 1 Ulnar nerve conduction velocities in patients with Leigh's syndrome. Bars represent the mean $\pm 2 S D$ values for normal infants.

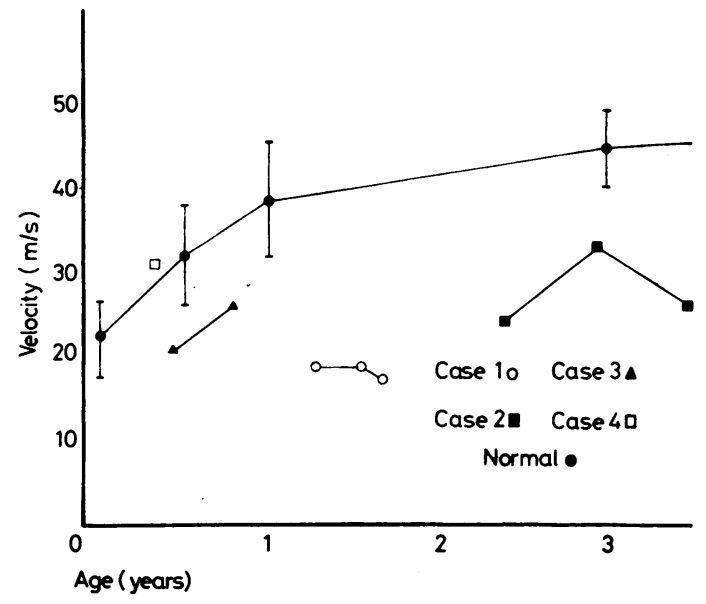

Fig. 2 Posterior tibial nerve conduction velocities in patients with Leigh's syndrome. except Case 4 had velocities well below that expected for their ages. In Case 1 the velocities were reduced by more than $50 \%$ and they did not change after treatment with thiamine hydrochloride. In Case 2 the velocities were also reduced by about $50 \%$ but one week after treatment with thiamine tetrafophoral disulphide (TTFD) there was an improvement by about $30 \%$ in the velocities. Case 3 at $3 \frac{1}{2}$ weeks age showed a value which is reduced by a third of the normal. At 9 months it is still slow. This child receives no treatment. Case 4 showed normal velocities for his age.

\section{Discussion}

The diagnosis of Leigh's syndrome was suspected in all 4 cases but in only 2 of the patients was there necropsy confirmation. Diagnosis in the other 2 patients however is beyond doubt because of the clinical and biochemical abnormalities, the presence of the inhibitor in one of the 2 affected sibs as well as one of his parents, and the absence of any other recognisable cause for the clinical picture.

The presence of slowed motor nerve conduction velocities in 3 of the 4 patients described suggests that peripheral neuropathy probably occurs more frequently in patients with Leigh's syndrome than is recognised. Although evidence of demyelination in peripheral nerve has been found at necropsy (Reye, 1960; Namiki, 1965; Jellinger et al., 1973), few reports mention motor nerve conduction studies. One of the 2 patients described by Robinson et al. (1967) had slowed motor nerve conduction while the other had widespread fibrillation potentials on electromyography. The patient described by Dunn and Dolman (1969) had slowed motor nerve conduction which returned to normal during remission.

Case 3 in this report already had slowed motor nerve conduction velocities at $3 \frac{1}{2}$ weeks of age. At 9 months it was still slow although he is clinically normal apart from lactic acidosis. This indicates that the peripheral neuropathy precedes the development of the overt signs of the disease and may be of value in the diagnosis of asymptomatic sibs of affected patients.

Slowed motor nerve conduction, however, is not found in every case of Leigh's syndrome. The one patient who had normal nerve conduction velocities also had an atypical mode of presentation with onset at birth, or even before birth, and development of spastic diplegia. It is possible that the cause of this child's disease was different from that of the other 3. The finding of slow motor nerve conduction velocity in these 3 patients is in keeping with evidence that 
Leigh's syndrome is due to an inborn error of thiamine metabolism (Cooper et al., 1969), since peripheral neuropathy is a well recognised complication of nutritional thiamine deficiency states. Thiamine hydrochloride in pharmacological doses however had no effect on the motor nerve conduction of one patient (Case 1).

Of particular interest, however, was the increase in conduction velocity in Case 2 of $33 \%$ and $38 \%$ in the ulnar and posterior tibial nerves respectively one week after starting TTFD. This is more than can be explained by the error inherent in the technique of nerve conduction measurement. The results of nerve conduction studies in this laboratory are reproducible (by the same observer) to within $10 \%$. It is possible that the TTFD which is taken up into the nervous system more readily than thiamine hydrochloride, may have been responsible for the increase in velocities. However, the increased velocities were not maintained, and this may be related to the difficulty in maintaining adequate levels of thiamine in the cerebrospinal fluid from continued use of TTFD (J. R. Cooper, personal communication, 1975).

Leigh's syndrome is a rare disorder but it is hoped that this paper will stimulate both paediatricians and paediatric neurologists to pay more attention to the peripheral nervous system in this disease, and in particular to look at possible correlations between peripheral nerve involvement and abnormalities of thiamine metabolism and response to treatment.

I am grateful to Professor J. R. Cooper (Yale University) for performing inhibitor assays, to Professor H. McIlwain of the Institute of Psychiatry (London) for the RBC transketolase assays, and to my paediatric colleagues for referring these patients.
References

Cooper, J. R., Itokawa, Y., and Pincus, J. H. (1969). Thiamine triphosphate deficiency in subacute necrotizing encephalomyelopathy. Science, 164, 74-75.

Dunn, H. G., and Dolman, C. L. (1969). Necrotizing encephalomyelopathy. Report of a case with relapsing polyneuropathy and hyperalaninemia and with manifestations resembling Friedreich's ataxia. Neurology, 19, 536-550.

Dunn, H. G., Lake, B. D., Dolman, C. L., and Wilson, J. (1969). The neuropathy of Krabbe's infantile cerebral sclerosis (globoid cell leucodystrophy). Brain, 92, 329-344.

Fullerton, P. M. (1964). Peripheral nerve conduction in metachromatic leucodystrophy (sulphatide lipidosis). Journal of Neurology, Neurosurgery and Psychiatry, 27, 100-105.

Gamstorp, I. (1968). Polyneuropathy in childhood. Acta Paediatrica Scandinavica, 57, 230-238.

Jellinger, K., Zimprich, H., and Muller, D. (1973). Relapsing form of subacute necrotizing encephalomyelopathy. Neuropädiatrie, 4, 314-321.

Kocen, R. S., and Thomas, P. K. (1970). Peripheral nerve involvement in Fabry's disease. Archives of Neurology, 22, 81-88.

Moosa, A. (1975). Peripheral neuropathy in Leigh's encephalomyelopathy. Developmental Medicine and Child Neurology, 17, 621-624.

Moosa, A., and Dubowitz, V. (1970). Peripheral neuropathy in Cockayne's syndrome. Archives of Disease in Childhood, 45, 674-677.

Namiki, H. (1965). Subacute necrotizing encephalomyelopathy. Case report with special emphasis on associated pathology of peripheral nervous system. Archives of Neurology, 12, 98-107.

Pincus, J. H., Itokawa, Y., and Cooper, J. R. (1969). Enzymeinhibiting factor in subacute necrotizing encephalomyelopathy. Neurology, 19, 841-845.

Reye, R. D. K. (1960). Subacute necrotizing encephalomyelopathy. Journal of Pathology and Bacteriology, 79, 165-173.

Robinson, F., Solitaire, G. B., Lamarche, J. B., and Levy, L. L. (1967). Necrotizing encephalomyelopathy of childhood. Neurology, 17, 472-484.

Correspondence to Dr A. Moosa, Department of Paediatrics and Child Health, Somerset Hospital, Beach Road, Green Point, Cape, South Africa. 